\title{
Neutral endopeptidase inhibition with inhaled phosphoramidon: no effect on bronchial responsiveness to adenosine $5^{\prime}$-monophosphate (AMP) in asthma
}

\author{
R. Polosa, G. Santonocito, S. Magrì, G. Paolino, F. Armato, C. Pagano, N. Crimi
}

\begin{abstract}
Neutral endopeptidase inhibition with inhaled phosphoramidon: no effect on bronchial responsiveness to adenosine 5'-monophosphate (AMP) in asthma. R. Polosa, G. Santonocito, S. Magrì, G. Paolino, F. Armato, C. Pagano, N. Crimi. ( ) ERS Journals Ltd 1997.

ABSTRACT: Part of the contractile response of adenosine in the asthmatic airways may be due to the activation of peptidergic pathways with subsequent local release of spasmogenic neuropeptides. At present, little is known about the potential role of lung peptidases in modulating adenosine-induced airway dysfunction in humans in vivo. We have, therefore, investigated the change in bronchial reactivity to adenosine 5'-monophosphate (AMP), after treatment with inhaled phosphoramidon, a potent neutral endopeptidase (NEP) inhibitor, in a double-blind, placebo-controlled, randomized study of 12 asthmatic subjects.

Subjects attended on six separate occasions, during which concentration response studies with inhaled AMP and methacholine were carried out, initially in the absence of treatment and then after nebulized phosphoramidon sodium salt $\left(1^{-5} \mathrm{M}\right)$ or matched placebo 5 min prior to a bronchoprovocation test with AMP or methacholine. Agonist responsiveness was expressed as the provocative concentration of AMP or methacholine producing a $20 \%$ fall in FEV1 from baseline (PC20,AMP or PC20,meth, respectively).

When compared to placebo, phosphoramidon failed to potentiate the airway response to AMP. The geometric mean (range) PC20 AMP value of 23.4 (4.4-190.6) $\mathrm{mg} \cdot \mathrm{mL}^{-1}$ after placebo was not significantly different from that of $20.7(4.5-100.9)$ mg.mL $\mathbf{m}^{-1}$ obtained after phosphoramidon.

The lack of change in bronchial reactivity to adenosine 5'-monophosphate after phosphoramidon indicates that endogenous airway neutral endopeptidase may not be of physiological importance in modulating the contractile response of adenosine in the airways. Thus, the present data do not support the view that activation of peptidergic pathways with subsequent local release of spasmogenic neuropeptides is important in the airway response to adenosine

Eur Respir J 1997; 10: 2460-2464.
\end{abstract}

Istituto Malattie Apparato Respiratorio, Università di Catania, Catania, Italy.

Correspondence: R. Polosa

Istituto Malattie Apparato Respiratorio

Università di Catania

Via Passo Gravina 187

95125 Catania

Italy

Keywords: Adenosine

asthma

bronchoconstriction

phosphoramidon

Received: October 211996

Accepted after revision June 301997
Adenosine and its related nucleotide, adenosine 5'monophosphate (AMP), provoke dose-dependent bronchoconstriction when inhaled by asthmatic subjects [1]. Adenosine potentiates the release of the preformed mediators, $\beta$-hexosaminidase and histamine, from immunologically activated rodent [2] and human lung [3] mast cells in vitro through an interaction with specific cell surface purinoceptors. That mast cell mediator release is a major cause of AMP-induced bronchoconstriction in asthma is also supported by the effective inhibition of the response with antihistamines and cyclo-oxygenase inhibitors [4-6]. However the contribution of alternative mechanisms (other than mast cell mediator release) has been suggested.

Activation of neural pathways may also contribute to the contractile airway response to adenosine in asthma. In isolated rabbit bronchial smooth muscle, adenosine potentiates the constrictor response to transmural nerve stimulation [7], and, in inbred rats, the changes in airway response provoked by intravenous adenosine have a significant atropine-sensitive component [8]. It is also possible that at least some of the reported protection afforded against the airways effect of adenosine by cromones [9, 10] and loop diuretics administered by inhalation is due to their ability to inhibit peptidergic neural reflexes [11]. In addition, it has been shown that the adenosine-induced bronchoconstriction in guineapigs in vivo may well have a capsaicin-sensitive component [12], thus indicating that release of contractile neuropeptides from sensory nerve endings might be of some importance in mediating the airway effects of purine derivatives. In support of this view, it has been demonstrated that AMP shows some degree of cross-tachyphylaxis with bradykinin in asthmatic subjects [13].

Neutral endopeptidase (NEP, also known as E.C. 3.4.24.11) is a membrane-bound enzyme normally found in the lung at the level of airway epithelium, which cleaves several bioactive peptides, including neurokinin A and substance $\mathrm{P}$ [14]. These neuropeptides cause bronchoconstriction and have been implicated in asthma [15]. Inhibition of NEP by drugs such as phosphoramidon or thiorphan markedly potentiates the bronchoconstrictor effects of these neuropeptides in asthmatic subjects [16, 17] 
Recently we have shown that the enhancing effect of NEP blockade with inhaled phosphoramidon on bradykinin-induced bronchoconstriction is the result of NEP metabolizing endogenous neuropeptides released by bradykinin [18]. Therefore, if adenosine 5'-monophosphate (AMP) elicits bronchoconstriction by releasing neuropeptides from sensory nerve endings, then effective NEP blockade should enhance the airways response to subsequent inhalation of AMP. This hypothesis was investigated by evaluating the effect of inhibiting endogenous NEP activity by inhaled phosphoramidon on AMP-induced bronchoconstriction in 12 asthmatic subjects in a double-blind, randomized, placebo-controlled study. The effect of phosphoramidon on methacholineinduced reactivity was also assessed to rule out possible nonspecific effects of such an agent on basal airway responsiveness.

\section{Methods}

\section{Subjects}

Twelve asthmatic subjects (five females and seven males), with a mean $( \pm$ SEM) age of $29( \pm 2)$ yrs, referred to the chest clinic of our hospital with stable asthma as defined by the American Thoracic Society [19], participated in the study (table 1). All subjects had a history of dyspnoea with wheezing or chest-tightness upon exposure to airborne allergens and were nonsmokers with positive skin-prick tests ( $>3 \mathrm{~mm}$ weal response) to one or more of six common aeroallergens (Dermatophagoides pteronyssinus, Dermatophagoides farinae, wall pellitory grass, mixed grass pollens, cat fur, dog hair). At the beginning of the study, all subjects were asymptomatic, with a baseline forced expiratory volume in one second $(\mathrm{FEV} 1)>70 \%$ of their predicted value. None had received oral corticosteroids, antihistamines or sodium cromoglycate within the preceding 3 weeks. Inhaled bronchodilators were discontinued for at least $8 \mathrm{~h}$ prior to each visit to the laboratory, although subjects were allowed

Table 1. - Demographic details of subjects studied

\begin{tabular}{|c|c|c|c|c|c|c|}
\hline $\begin{array}{l}\text { Ss } \\
\text { No. }\end{array}$ & Sex & $\begin{array}{l}\text { Age } \\
\text { yrs }\end{array}$ & $\begin{array}{c}\text { Baseline FEV1 } \\
\% \text { pred }\end{array}$ & Atopy $§$ & $\begin{array}{c}\text { PC20,meth } \\
\mathrm{mg} \cdot \mathrm{mL}^{-1}\end{array}$ & Regular medication \\
\hline 1 & M & 18 & 118 & $\mathrm{D}$ & 0.25 & \\
\hline 2 & $\mathrm{~F}$ & 44 & 89 & W & 1.17 & $\mathrm{~S}$ \\
\hline 3 & $\mathrm{M}$ & 26 & 84 & W, D & 1.01 & $\mathrm{~S}$ \\
\hline 4 & $\mathrm{M}$ & 28 & 75 & D & 5.71 & $\mathrm{~S}, \mathrm{BDP}(2000 \mu \mathrm{g})$ \\
\hline 5 & $\mathrm{M}$ & 30 & 91 & $\mathrm{D}$ & 0.12 & $\mathrm{~S}, \mathrm{BDP}(1000 \mu \mathrm{g})$ \\
\hline 6 & $\mathrm{~F}$ & 31 & 96 & W, D & 2.25 & \\
\hline 7 & $\mathrm{~F}$ & 24 & 90 & W & 0.87 & $\mathrm{~S}$ \\
\hline 8 & M & 35 & 71 & D & 1.96 & $\mathrm{~S}$ \\
\hline 9 & $\mathrm{~F}$ & 28 & 84 & W, D & 0.19 & $\mathrm{~S}, \mathrm{BDP}(2000 \mu \mathrm{g})$ \\
\hline 10 & $\mathrm{M}$ & 27 & 94 & $\mathrm{~W}, \mathrm{G}$ & 0.98 & \\
\hline 11 & M & 35 & 89 & W & 0.64 & $\mathrm{~S}$ \\
\hline 12 & $\mathrm{~F}$ & 26 & 89 & W & 2.97 & $\mathrm{~S}, \mathrm{BDP}(1000 \mu \mathrm{g})$ \\
\hline \multirow{2}{*}{\multicolumn{2}{|c|}{ Mean }} & 29 & 89 & & $0.90^{+}$ & \\
\hline & & \pm 2 & \pm 3 & & $(0.12-5.71)$ & \\
\hline
\end{tabular}

Ss: subjects; M: male; F: female; D: Dermatophagoides; W: wall pellitory; G: grass; FEV1: forced expiratory volume in one second; $\mathrm{PC} 20$,meth: provocation concentration of methacholine producing a $20 \%$ fall in FEV1; S: salmeterol p.r.n.; BDP: beclomethasone dipropionate. ${ }^{+}$: geometric mean, and range in parenthesis; $\$$ : atopic, positive immediate skin-prick test to one or more allergens. to continue inhaled corticosteroids as usual (table 1). The study was approved by the Ethics Committee of the Dept of Respiratory Diseases. All subjects gave their informed consent.

\section{Bronchial provocation}

Pulmonary function was measured before and during the provocation as the FEV1, using a dry wedge spirometer (Vitalograph ${ }^{\circledR}$, Buckinghamshire, UK), the first of two consecutive measurements being used for analysis. Methacholine (Sigma Chemical Co., St Louis, USA) and AMP (Sigma Chemical Co.) were made up in $0.9 \%$ sodium chloride to produce a range of increasing doubling concentrations of $0.03-64.00 \mathrm{mg} \cdot \mathrm{mL}^{-1}(0.2-327$ $\mathrm{mM})$ and $0.78-800 \mathrm{mg} \cdot \mathrm{mL}^{-1}(8.96-1,151.4 \mathrm{mM})$, respectively. The solutions were administered as aerosols generated from a starting volume of $3 \mathrm{~mL}$ in a disposable Inspiron mini-nebulizer (C.R. Bard International, Sunderland, UK) driven by compressed air at $8 \mathrm{~L} \cdot \mathrm{min}^{-1}$. Under these conditions, the nebulizer has an output of $0.48 \mathrm{~mL} \cdot \mathrm{min}^{-1}$ and generates an aerosol with a mass median particle diameter of $4.7 \mu \mathrm{m}$ [20]. Wearing a noseclip, subjects inhaled the aerosolized solutions via a mouthpiece as five breaths from end-tidal volume to full inspiratory capacity [21].

\section{Study design}

The study consisted of two separate phases. In the first phase, subjects attended the laboratory on two separate occasions, at least $48 \mathrm{~h}$ apart, to undertake concentration-response studies with inhaled methacholine and AMP in the absence of any drug treatment. On the first occasion, after $15 \mathrm{~min}$ rest, three baseline measurements of FEV1 were made at 3 min intervals followed by inhalation of $0.9 \%$ sodium chloride. Repeat FEV1 measurements were made at 1 and $3 \mathrm{~min}$, the higher value being recorded. Provided the FEV1 did not fall by $>10 \%$ of the baseline value, a methacholine concentration-response study was carried out. After administration of each methacholine concentration, FEV1 was measured at 1 and 3 min. Increasing doubling concentrations of methacholine were inhaled at 5 min intervals until FEV1 had fallen by $>20 \%$ of the postsaline value. The fall in FEV1 following each concentration of agonist was expressed as a percentage of the higher of the two postsaline baseline FEV1 recordings. The percentage fall in FEV1 was plotted against the cumulative concentration of agonist on a logarithmic scale, and the provocation concentration required to produce a $20 \%$ decrease in FEV1 from the postsaline baseline value (PC20) was determined by linear interpolation. On the second occasion, a bronchial provocation test with inhaled AMP was undertaken in a similar 
manner to that described for methacholine. FEV1 measurements were recorded 1 and 3 min after inhalation of each concentration of AMP and the corresponding PC20 FEV1 values derived.

In the second phase, subjects attended the laboratory on four separate visits, at least 5 days apart, to undertake concentration-response studies with inhaled AMP and methacholine after receiving nebulized phosphoramidon (Sigma Chemical Co., St Louis, USA) or matched nebulized vehicle placebo administered double-blind and in random order $5 \mathrm{~min}$ prior to challenge. Both the active and placebo solutions were freshly prepared by an independent investigator on the basis of a randomized code, and then returned to the conducting physician to administer to the attending subject. On each occasion, after $15 \mathrm{~min}$ rest, three baseline measurements of FEV1 were made at intervals of $3 \mathrm{~min}$, followed by inhalation of $3 \mathrm{~mL}$ nebulized phosphoramidon $\left(10^{-5} \mathrm{M}\right)$ or nebulized vehicle placebo consisting of $0.9 \%$ sodium chloride adjusted to a similar $\mathrm{pH}$ and toxicity as the phosphoramidon. The aerosol solutions were generated from a starting volume of $3.0 \mathrm{~mL}$ in an Inspiron mini-nebulizer driven by compressed air at $8 \mathrm{~L} \cdot \mathrm{min}^{-1}$, and inhaled to dryness by deep tidal breathing over a 7-9 min time period. The same nebulizer was used for all studies on all subjects. Further FEV1 measurements were repeated at 2 and $5 \mathrm{~min}$ after drug/placebo inhalation and doseresponse studies with increasing concentrations of AMP and methacholine were carried out in a similar manner to that described in phase 1 .

\section{Data analyses}

Results are expressed as mean \pm SEM unless otherwise stated, and a p-value $<0.05$ was accepted as the minimum level for statistical significance. Pre- and posttreatment baseline values of FEV1 prior to bronchial challenges were compared within each study day using the Student's t-test for paired data and between study days by two-way analysis of variance (ANOVA).

Concentration-response curves were constructed by plotting the percentage change in FEV 1 from the postdiluent baseline value against the cumulative concen- tration of the agonist administered on a logarithmic scale. The PC20 was determined by linear interpolation. Values of PC20 for AMP (PC20,AMP) and for methacholine (PC20,meth) following treatment with phosphoramidon and placebo were logarithmically transformed to normalize their distribution and were compared using the Student's t-test for paired data.

Power calculations, based on the assumption that a significant leftward shift in the dose-response curve for AMP is approximately one doubling dose, indicate that for the 12 subjects studied there is a $90 \%$ chance of detecting a significant difference with a significance level of $<5 \%$ (two-sided).

\section{Results}

There were no significant differences in mean baseline values of FEV 1 between any of the study days. Inhaled phosphoramidon was well-tolerated and had no effect on baseline FEV1.

In phase 1, inhaled AMP and methacholine produced concentration-related falls in FEV1. The geometric mean (range) of PC20 values obtained were 23.8 (4.8-181.5) and $0.90(0.12-5.71) \mathrm{mg} \cdot \mathrm{mL}^{-1}$ for AMP and methacholine, respectively (table 2 ). In phase 2 , inhaled phosphoramidon failed to alter the airway response to a subsequent inhalation with AMP and methacholine in the subjects studied (table 2). The geometric mean (range) PC20,AMP of $23.4(4.4-190.6) \mathrm{mg} \cdot \mathrm{mL}^{-1}$ after placebo was not significantly different from that of 20.7 (4.5-100.9) $\mathrm{mg} \cdot \mathrm{mL}^{-1}$ obtained after phosphoramidon. In addition, the geometric mean (range) PC20, meth after placebo was $0.75(0.11-5.78) \mathrm{mg} \cdot \mathrm{mL}^{-1}$ which did not differ significantly from the value of $0.76(0.15-10.66)$ $\mathrm{mg} \cdot \mathrm{mL}^{-1}$ obtained on the phosphoramidon study day.

\section{Discussion}

In the asthmatic subjects studied, inhibition of NEP by inhaled phosphoramidon failed to elicit any significant enhancement of the bronchospastic response provoked by AMP. These findings support the view that release of endogenous neuropeptides do not contribute

Table 2. - Effects of pretreatment with inhaled phosphoramidon and placebo on airway adenosine 5'monophosphate (AMP) and methacholine responsiveness

\begin{tabular}{|c|c|c|c|c|c|c|}
\hline \multirow{2}{*}{$\begin{array}{l}\text { Ss } \\
\text { No. }\end{array}$} & \multicolumn{3}{|c|}{ PC20,AMP $\mathrm{mg} \cdot \mathrm{mL}^{-1}$} & \multicolumn{3}{|c|}{ PC20,meth $\mathrm{mg} \cdot \mathrm{mL}^{-1}$} \\
\hline & Baseline & Placebo & Phosphoramidon & Baseline & Placebo & Phosphoramidon \\
\hline 1 & 7.7 & 7.6 & 7.3 & 0.25 & 0.11 & 0.15 \\
\hline 2 & 11.0 & 12.0 & 11.7 & 1.17 & 0.58 & 0.44 \\
\hline 3 & 11.7 & 11.0 & 9.9 & 1.01 & 0.77 & 1.73 \\
\hline 4 & 102.0 & 40.6 & 90.9 & 5.71 & 5.78 & 10.66 \\
\hline 5 & 34.7 & 38.0 & 51.7 & 0.12 & 0.43 & 0.65 \\
\hline 6 & 181.5 & 190.6 & 100.9 & 2.25 & 2.78 & 0.74 \\
\hline 7 & 43.3 & 46.9 & 46.5 & 0.87 & 0.26 & 0.44 \\
\hline 8 & 20.2 & 21.4 & 15.8 & 1.96 & 1.66 & 1.18 \\
\hline 9 & 4.8 & 4.4 & 4.5 & 0.19 & 0.19 & 0.25 \\
\hline 10 & 12.3 & 19.6 & 5.6 & 0.98 & 0.93 & 0.55 \\
\hline 11 & 25.3 & 25.1 & 22.7 & 0.64 & 0.51 & 0.43 \\
\hline 12 & 42.5 & 42.1 & 35.9 & 2.97 & 2.85 & 2.05 \\
\hline Geometric mean & 23.8 & 23.4 & 20.7 & 0.90 & 0.75 & 0.76 \\
\hline Range & (4.8-181.5) & $(4.4-190.6)$ & (4.5-100.9) & $(0.12-5.71)$ & $(0.11-5.78)$ & $(0.15-10.66)$ \\
\hline
\end{tabular}

PC20,AMP, PC20,meth: provocative concentration of AMP or methacholine, respectively, producing a $20 \%$ fall in forced expiratory volume in one second (FEV1); Ss: subjects. 
to the airways effect of adenosine in asthmatic airways in vivo. In addition, NEP blockade had no effect on airways responsiveness to the muscarinic receptor agonist, methacholine, indicating that a functional NEP system if present is not important in modulating nonspecific airway hyperresponsiveness. This finding is in agreement with previous work, which demonstrated lack of change in histamine reactivity after phosphoramidon in asthmatic airways [18].

Although we were unable to demonstrate any effect of inhaled phosphoramidon on AMP-induced bronchoconstriction, it must be pointed out that the dosage of phosphoramidon used in the present study and the timing of administration before bronchial challenge has been shown to significantly potentiate the bronchospastic response to neurokinin A (NKA) and bradykinin in asthmatic subjects $[17,18]$.

The lack of an important modulatory role of the NEP system in the airways response to exogenously administered AMP may be in agreement with previous data by CRIMI et al. [18] on the lack of change in histamine reactivity after phosphoramidon in asthmatic subjects. Indeed, if we consider that NEP inhibition has no effect on histamine and that AMP is acting mainly through releasing histamine from airways mast cells, then a lack of effect of phosphoramidon on adenosine response is not surprising.

NEP is not the only lung peptidase involved in the degradation of neuropeptides; several observations indicate that angiotensin converting enzyme (ACE, also known as E.C. 3.4.15.1) may also contribute to the control of neuropeptide activity in the airways [22, 23]. In rat tracheal mucosa, both NEP and ACE inhibitors potentiate the effect of neuropeptides on vascular permeability [23]. When the combination of NEP and ACE inhibitors was used together, potentiation of the effect of neuropeptides on plasma extravasation was greater than that obtained with a maximally effective dose of either inhibitor by itself. This suggests that when only one peptidase is inhibited, the remaining enzyme may still limit the activity of neuropeptides, thus compensating for the loss of functional activity of the other peptidase. Therefore, despite the fact that phosphoramidon is a potent inhibitor of NEP, the lack of change in AMP reactivity after NEP inhibition may be the result of the hydrolysis of neuropeptides by other lung peptidases, such as ACE and carboxypeptidase $\mathrm{M}$ and $\mathrm{N}$, suggesting the importance of alternative enzymatic pathways.

In conclusion, the present study shows that phosphoramidon given by inhalation is not effective in enhancing the bronchoconstrictor response of adenosine 5'-monophosphate, thus suggesting that local release of contractile neuropeptides from sensory nerve endings may not be important in mediating the airway effects of adenosine. Although neutral endopeptidase activity has no physiological importance in regulating airway responsiveness to adenosine in asthma in vivo, other lung peptidases may have a more prominent role in the control of adenosine-driven changes in airway function. Unfortunately, the present data have not thrown a definite light on the hypothesis that neuropeptides released from sensory nerve endings contribute to adenosine 5'-monophosphate-induced bronchoconstriction in human asthma and further work is required.

\section{References}

1. Cushley MJ, Tattersfield AE, Holgate ST. Inhaled adenosine and guanosine on airway resistance in normal and asthmatic subjects. Br J Clin Pharmacol 1983; 15: 161-165.

2. Marquardt DL, Walker LL, Waserman SI. Adenosine receptors on mouse bone-marrow derived mast cells: functional significance and regulation by aminophylline. $J$ Immunol 1984; 133: 932-937.

3. Hughes PJ, Holgate ST, Church MK. Adenosine inhibits and potentiates IgE-dependent histamine release from human lung mast cells by an $\mathrm{A}_{2}$-purinoceptor mediated mechanism. Biochem Pharmacol 1984; 33: 3847-3852.

4. Crimi N, Palermo F, Polosa R, et al. Effect of indomethacin on adenosine-induced bronchoconstriction. J Allergy Clin Immunol 1989; 83: 921-925.

5. Phillips GD, Holgate ST. The effect of oral terfenadine alone and in combination with flurbiprofen on the bronchoconstrictor response to inhaled adenosine 5'-monophosphate in nonatopic asthma. Am Rev Respir Dis 1989; 139: 463-469.

6. Crimi N, Polosa R, Magrì S, et al. Inhaled lysine-acetylsalicylate (LASA) attenuates the bronchoconstrictor response to AMP in asthmatic subjects. Eur Respir $J$ 1995; 8: 905-912.

7. Gustafsson LF, Wiklund NP, Cederqvist B. Apparent enhancement of cholinergic transmission in rabbit bronchi via adenosine $\mathrm{A}_{2}$-receptor. Eur J Pharmacol 1986; 120: 179-185.

8. Pauwels RA, Van der Straeten ME. An animal model for adenosine-induced bronchoconstriction. Am Rev Respir Dis 1987; 136: 374-378.

9. Crimi N, Palermo F, Oliveri R, et al. Comparative study of the effects of nedocromil sodium (4 mg) and sodium cromoglycate $(10 \mathrm{mg})$ on adenosine-induced bronchoconstriction in asthmatic subjects. Clin Allergy 1988; 18: 367-374.

10. Phillips GD, Scott VL, Richards R, Holgate ST. Effect of nedocromil sodium an sodium cromoglycate against bronchoconstriction induced by inhaled AMP. Eur Respir J 1989; 2: 210-217.

11. Polosa R, Rajakulasingam K, Prosperini G, Church MK, Holgate ST. Relative potencies and time-course of changes in adenosine 5'-monophosphate (AMP) airway responsiveness with inhaled frusemide and bumetanide in asthma. J Allergy Clin Immunol 1993; 92: 288-297.

12. Manzini S, Ballati L. 2-chloroadenosine induction of vagally-mediated and atropine-resistant bronchomotor responses in anaesthetised guinea-pigs. Br J Pharmacol 1990; 100: 251-256.

13. Polosa R, Rajakulasingam K, Church MK, Holgate ST. Repeated inhalation of bradykinin attenuates adenosine 5'-monophosphate (AMP) induced bronchoconstriction in asthmatic airways. Eur Respir J 1992; 5: 700-706.

14. Borson DB. Roles of neutral endopeptidase in airways. Am J Physiol (Lung Cell Mol Physiol) 1991; 4: L212-L225.

15. Barnes PJ. Asthma as an axon reflex. Lancet 1986; 1 : 242-245.

16. Cheung D, Timmers MC, Zwinderman AH, den Hartigh J, Dijkman JH, Sterk PJ. Neutral endopeptidase activity and airway hyperresponsiveness to neurokinin A in asthmatic subjects in vivo. Am Rev Respir Dis 1993; 148: $1467-1473$

17. Crimi N, Palermo F, Oliveri R, Polosa R, Magrì S, Mistretta A. Inhibition of NEP potentiates bronchoconstriction induced by neurokinin $\mathrm{A}$ in asthmatic patients. Clin Exp Allergy 1994; 24: 115-120. 
18. Crimi N, Polosa R, Pulvirenti G, et al. Effect of inhaled NEP inhibitor, phosphoramidon, on baseline airway calibre and bronchial responsiveness to bradykinin in asthma. Thorax 1995; 50: 505-510.

19. American Thoracic Society. Standards for the diagnosis and care of patients with COPD and asthma. Am Rev Respir Dis 1987; 136: 225-244.

20. Lewis RA. Therapeutic aerosols. In: Cumming G, Bonsignore $\mathrm{C}$ eds. Drugs and the Lung. London, Plenum Publishing Co., 1984: pp. 63-86.
21. Chai H, Farr RS, Froehlich LA, et al. Standardization of bronchial inhalation challenge procedures. J Allergy Clin Immunol 1975; 56: 323-327.

22. Skidgei RA, Engelbrecht S, Johnson AR, Erdos EG. Hydrolysis of substance P and neurotensin by ACE and neutral endopeptidase. Peptides (Elmsford) 1984; 5: 769-776.

23. Piedimonte G, McDonald DM, Nadel JA. Neutral endopeptidase and kininase II mediate glucocorticoid inhibition of neurogenic inflammation in the rat trachea. J Clin Invest 1991; 88: 40-44. 